\title{
Causal grounds for negative truths
}

\author{
Robin Stenwall ${ }^{1}$ (D)
}

Published online: 3 December 2016

(c) The Author(s) 2016. This article is published with open access at Springerlink.com

\begin{abstract}
Among truthmaker theorists it is generally thought that we are not able to use the entailment principle (i.e. the principle according to which truthmaking distributes across entailment) to ground negative truths. But these theorists usually only discuss truthmakers for truth-functional complexes, thereby overlooking the fact that there are non-truth-functional complexes whose truth values are not solely determined by the truth or falsity of their atomic propositions. And once we expand the class of truths that require their own bespoke truthmakers to also include these, there is no reason to exempt negative truths from grounding. For given that truthmaking is closed under entailment and every negative truths is entailed by some non-truth-functional complex or other, any resources rich enough to ground the truth of the latter will do the same job for the former.
\end{abstract}

Keywords Truthmaking - Causation · Grounding · Negative truth · Maximalism

\section{Introduction}

Let us, following Armstrong (2004, pp. 5-7), call the view that every true proposition has a truthmaker, Truthmaker Maximalism. Some truthmaker theorists deny maximalism in view of negative truths. In logical atomism, for example, the truth value of a truth-functional complex is explained in terms of its logical structure and the truth or falsity of its atomic propositions. This has led some philosophers to argue that true truth-functions do not need bespoke truthmakers: all it takes to fix the truth value of a truth-functional complex is to fix the truth value of its simpler constituents. A prominent advocate of this position is Hugh Mellor. He says:

Robin Stenwall

robin.stenwall@fil.lu.se

1 Department of Philosophy, Lund University, Box 192, 22100 Lund, Sweden 
Some $[\ldots]$ truths need no truthmakers, notably true truth-functions, whose truth follows from the truth values of their constituents. We may say of course that

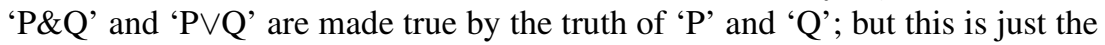
entailment of one proposition by others, not the "cross-categorial" link between propositions and other entities that concerns us here. That is what true truthfunctions do not need and therefore, I claim, do not have [...] In particular negative truth-functions do not need them, since if ' $\mathrm{P}$ ' is made true by $\mathrm{S}$, all it takes to make 'P' false and hence ' $\sim \mathrm{P}$ ' true is that $\mathrm{S}$ not exist (2002a, p. 213).

The idea is that if the truth of a complex proposition is a function of its constituent atomic propositions, it is to the truthmakers of these latter propositions only that we must turn when outlining a theory of the basic structure of the world. In the passage, Mellor can be read as taking this to imply that truth-functional complexes do not have truthmakers, period. This would be mistaken. Rather, the claim is that there is no need to postulate anything in addition to what make the constituent propositions true. Thus, there is no need to postulate, say, the existence of a conjunctive entity that makes $\langle\mathrm{P} \wedge \mathrm{Q}\rangle$ true $^{1}$ : the conjunction is true simply in virtue of there being a truthmaker for each conjunct. Nor do we need a disjunctive entity that makes $\langle\mathrm{P} \vee \mathrm{Q}\rangle$ true: it suffices that there is a truthmaker for either disjunct. Now consider $\langle\sim \mathrm{P}\rangle$. It is also a complex, of a negation and an atomic proposition. So is there an analogous case to be made for negative truths? Mellor seems to think that there is. All it takes for $\langle\sim \mathrm{P}\rangle$ to be true is that $\langle\mathrm{P}\rangle$ is not made true by anything. As with the conjunction and disjunction case, there is no need for a separate truthmaker, some sort of negative entity, to make $\langle\sim \mathrm{P}\rangle$ true. A negative proposition is true just in case the corresponding positive proposition lacks a truthmaker. ${ }^{2}$

If this were correct there would be no need to uphold maximalism. But Mellor's argument can be resisted. In the conjunction and disjunction case, truthmaking distributes across entailment: there is no need to postulate the existence of separate truthmakers for $\langle\mathrm{P} \wedge \mathrm{Q}\rangle$ and $\langle\mathrm{P} \vee \mathrm{Q}\rangle$, because we already have truthmakers for atomic truths, and these entail the truth of the corresponding complexes. But, in the case of negation, matters are quite different. Here $\langle\sim \mathrm{P}\rangle$ is supposed to be true because nothing makes the more atomic proposition $\langle\mathrm{P}\rangle$ true. This asymmetry is worrying, since it seems to undermine not just maximalism, but truthmaker theory altogether. Ross Cameron explains why:

If we don't get the negative truths for free given the positive truths, then what possible motivation could there be for accepting that some truths require truthmakers but that negative truths don't? That would be to accept that the negative truths are not true in virtue of anything: but if we allow that then why do we not allow positive truths that are not true in virtue of anything? It's one thing to say that certain truths are obtained for free given our grounding of other truths, and hence that they don't need further grounding: it's another

\footnotetext{
$1^{1}$ I adopt the custom of letting ' $\langle\mathrm{P}\rangle$ ' stand for the 'proposition that $\mathrm{P}$ '.

2 As Mellor (2002b) points out, no claim is being made to the effect that we can always tell which, if either, of $\langle\mathrm{P}\rangle$ or $\langle\sim \mathrm{P}\rangle$ expresses an atomic proposition: if either does, it will be the one that does have a truthmaker.
} 
thing altogether to say that certain truths just aren't grounded. Either there's something wrong with accepting truths that don't have an ontological grounding or there isn't: if there is, then every truth requires grounding; if there isn't, then no truth requires grounding (2008, p. 411).

I think that Cameron is right about this. Truthmaker theory is about the groundedness of truth. As such, it is not the kind of theory that can apply only in a restricted domain (at least with respect to synthetic truths). However, I don't think that all hope is lost for the logical atomist. The grounding asymmetry arises as a result of the fact that among the truth-functional complexes, it is only the negative truths that are meant to be true because there is nothing making the more atomic propositions true. The truth of all the other complexes bottoms out in existent entities in the form of truthmakers for their atomic constituents. But then, what if one could provide ontological grounds for negative truths, not in the truthmakers for their atomic constituents (since these are non-existent), but in the truthmakers for complexes that entail negative truths? Cameron considers this strategy, but rejects it on the following basis: "if we don't have a truthmaker for $\sim \mathrm{P}$ then we don't have a truthmaker for any truth that entails $\sim \mathrm{P}$ either: it's not as if truthmakers for $\sim \sim \sim$ P are any easier to find than truthmakers for $\sim$ P!" (2008, p. 411). Needless to say, this is correct provided that truth-functions do not need, and therefore (if Mellor is right) do not have, their own truthmakers to begin with. But it does not follow from this that only simple atomic propositions have truthmakers of their own. For even if truth-functions do not have them, other complexes may. Consider, for example, $\langle$ the chance of $\mathrm{P}$ is $p\rangle$, $\langle$ if $\mathrm{P}$ had been the case, then $\mathrm{Q}$ would be $\rangle$ and $\langle\mathrm{P}$ because $\mathrm{Q}\rangle$, all of which are non-truth-functional complexes whose truth values do not follow from those of their atomic constituents. And once we expand the class of truths that require their own separate truthmakers to include these, there is no reason to exempt negative truths from ontological grounding. For given that truthmaking is closed under entailment and every negative truth is entailed by some true non-truthfunctional complex or other, any resources rich enough to provide truthmakers for the latter will do the same job for the former. In Sects. 3 and 4, I will consider Mellor's non-relational view of causation to see whether it provides us with the means of grounding negative truths. First, however, we need to discuss, briefly, the sense in which I take truthmaking to distributes across entailment.

\section{Grounding and entailment}

In grounding the truth of truth-functional complexes in the truthmakers for their constituents, logical atomism trades on the so-called Entailment Principle, which states that:

(EP) if $\mathrm{T}$ makes $\langle\mathrm{P}\rangle$ true and $\langle\mathrm{P}\rangle$ entails $\langle\mathrm{Q}\rangle$, then $\mathrm{T}$ makes $\langle\mathrm{Q}\rangle$ true, ${ }^{3}$

\footnotetext{
3 In line with the spirit of logical atomism, I take it that several entities, however disparate, can jointly make true a proposition without there being a single entity doing the work alone. Hence, I shall allow ' $\mathrm{T}$ ' to state a list of more than one single term. One might object that whenever several entities seemingly
} 
where, on the classical view of entailment, $\langle\mathrm{P}\rangle$ entails $\langle\mathrm{Q}\rangle$ if and only if it is impossible for $\langle\mathrm{P}\rangle$ to be true and $\langle\mathrm{Q}\rangle$ false.

Attractive as (EP) might be in its ontological economy, it still has some undesirable consequences. Since every necessary truth is entailed by every truth and every entity makes some truth true, one consequence is that everything makes every necessary truth true. ${ }^{4}$ But this means, among other things, that the truthmaker for 〈Socrates exists〉 also serves as a truthmaker for all the truths of logic and mathematics, which is absurd. Truthmaking is the relation we invoke to explain why a proposition is true by reference to the existence of that which grounds its truth. ${ }^{5}$ And whatever grounds the truth of $\langle$ Hesperus is Phosphorus〉, 〈it either rains or it does not rain $\rangle$ and $\langle 2+2=4\rangle$, it is obvious that Socrates does not. Worse still, (EP) leads to the result that everything makes every truth true, whether necessary or contingent. All we have to assume is that a truthmaker for a disjunction must make either disjunct true. ${ }^{6}$ But apart from the absurdity of making Socrates the ontological basis for all truths, this trivializes the metaphysical project of finding ontological grounds for any given truth.

Various strategies to avoid these problems have been devised. Some theorists accept (EP) in its classical form but deny that a truthmaker for a disjunction must make one or other disjunct true (Read 2000, p. 75). This avoids the second problem, but not the first: everything would still be a truthmaker for every necessary truth. Besides, even if we somehow learn to live with this implication, we must (on pain of 'trivialization') accept truthmakers for disjunctions that fail to make either disjunct true. But this undermines the entire atomistic project of grounding the truth of truthfunctional complexes in the truthmakers for their constituent propositions.

\section{Footnote 3 continued}

make a proposition true, what does the truthmaking is really the mereological sum of those entities (cf. Armstrong 2004, p. 18). However, such a view would commit one to all sorts of weird fusions, the existence of which I wish to remain neutral on.

${ }^{4}$ Proof: Take any entity $\mathrm{T}$ and necessary truth $\langle\mathrm{Q}\rangle$. By assumption, there is some $\langle\mathrm{P}\rangle$ such that $\mathrm{T}$ makes $\langle\mathrm{P}\rangle$ true. Since $\langle\mathrm{Q}\rangle$ is necessary and so entailed by $\langle\mathrm{P}\rangle$, it follows from (EP) that $\mathrm{T}$ makes $\langle\mathrm{Q}\rangle$ true (Restall 1996, p. 333).

${ }^{5}$ Truthmaking, on this view, is a matter of grounding truth. More specifically, it is the kind of grounding relation that holds between a worldly non-propositional entity and a proposition. This view differs from Fine's (2012a), according to which truthmaking is not a case of grounding, although they are closely related. Fine himself, of course, thinks that grounding is an operation rather than a relation. But given that grounding is a relation, he thinks that it should be taken to obtain only between entities of the same kind (2012a: p. 43). This rules out truthmaking being a case of grounding since truthmaking is a crosscategorial relation that relates entities belonging to different kinds: a non-propositional entity $\mathrm{T}$ and a proposition $\langle\mathrm{P}\rangle$. But Fine does not provide any justification for his claim that grounding only relates entities belonging to the same kind. Thus, I will assume in accordance with Gonzalo Rodriguez-Pereyra (2015) and Jonathan Schaffer (2009: p. 375), that ground can link entities of different kinds, and more importantly, that in the case of truthmaking, it links a proposition $\langle\mathrm{P}\rangle$ with a non-propositional entity $\mathrm{T}$ that grounds $\langle\mathrm{P}\rangle$ 's truth (Armstrong 2004: p. 6).

${ }^{6}$ Proof: Let $\mathrm{T}$ be any entity and $\langle\mathrm{Q}\rangle$ any truth. By assumption, T makes some $\langle\mathrm{P}\rangle$ true. Since $\langle\mathrm{Q} \vee \sim \mathrm{Q}\rangle$ is necessary and so entailed by $\langle\mathrm{P}\rangle$, it follows from (EP) that $\mathrm{T}$ makes $\langle\mathrm{Q} \vee \sim \mathrm{Q}\rangle$ true. Given that a truthmaker for a disjunction is also a truthmaker for either disjunct, we obtain the result that $\mathrm{T}$ makes $\langle\mathrm{Q}\rangle$ true or T makes $\langle\sim \mathrm{Q}\rangle$ true. However, nothing makes $\langle\sim \mathrm{Q}\rangle$ true, because $\langle\sim \mathrm{Q}\rangle$ is false. So T makes $\langle\mathrm{Q}\rangle$ true (Restall 1996, p. 333). 
A more promising strategy for present purposes, and one favored by Armstrong (2004, pp. 10-11), is substituting some sort of relevant entailment for classical entailment in (EP), thus blocking the route from the necessity of $\langle\mathrm{Q}\rangle$ to its entailment by an arbitrary $\langle\mathrm{P}\rangle$. This enables us to avoid trivializing truthmaker theory without having to accept bespoke truthmakers for disjunctions. The problem here is that there are several systems of relevant logic, each one validating different entailments. To make (EP) precise one must specify what system of logic the notion of entailment in (EP) belongs to, and as Rodriguez-Pereyra (2006, p. 975) notes, there is no guarantee that any of these systems will have a notion that conforms to our conception of what makes what true. The guarantee is unavailable because the systems are not concerned with the groundedness of truth. Rather, they are concerned with how the notion of entailment functions in rational inference. This is why (EP), expressed in terms of relevant entailment, fails to identify rightful truthmakers. No system of relevant logic warrants an entailment from $\langle$ Socrates is white $\rangle$ to $\langle$ Socrates is colored $\rangle$, yet we would expect these propositions to share the same truthmaker.

Another strategy_offered by Frank Jackson and admired by Armstrong-is to hold on to classical entailment while narrowing the scope of (EP). The most natural suggestion is to restrict the principle to contingent truths. However, this will not do-at least, assuming that a truthmaker for a conjunction is a truthmaker for each conjunct. For then, everything would still make every necessary truth true. ${ }^{7}$ In response to this, Armstrong recommends on behalf of Jackson that we restrict (EP) to 'purely contingent' truths, i.e. truths which do not contain any necessary component at 'any level of analysis' (2004, pp. 11-12). This amounts to saying that when a proposition is a conjunction of a contingent truth and a necessary truth its entailment of the necessary truth is not allowed in (EP). Rather ad hoc, admittedly, but in the following I will assume that the restriction can be accepted as a mere (stipulative) refinement.

There is, however, a general objection to (EP), and this threatens to undermine all three of the above strategies to fix the principle. In any reasonable sense of 'entailment', conjunctions entail their conjuncts regardless of whether they are (purely) contingent or not. A consequence of (EP), no matter how it is amended, is thus that whenever a plurality of entities make a conjunction true, they make true each conjunct. Now, suppose that $\langle$ Socrates exists $\rangle$ and $\langle$ Plato exists $\rangle$ are made true by Socrates and Plato respectively, and thus that together they are what makes $\langle$ Socrates exists and Plato exists〉 true. Since the conjunction entails 〈Socrates exists $\rangle$, it follows from (EP) that Socrates and Plato together are the truthmaker for $\langle$ Socrates exists $\rangle$. But one may plausibly deny this on the grounds that a truthmaker is an entity in virtue of which a proposition is true, and that $\langle$ Socrates exists $\rangle$ is not true in virtue of Socrates and Plato taken together: it is true simply in virtue of Socrates (Rodriguez-Pereyra 2006, p. 972).

\footnotetext{
7 Proof: Let $\mathrm{T}$ be any entity and $\langle\mathrm{Q}\rangle$ be any necessary truth. By assumption, there is some contingent $\langle\mathrm{P}\rangle$ such that $\mathrm{T}$ makes $\langle\mathrm{P}\rangle$ true. Since $\langle\mathrm{P}\rangle$ entails $\langle\mathrm{P} \wedge \mathrm{Q}\rangle$ (because, by hypothesis, $\langle\mathrm{Q}\rangle$ is a necessary truth) and the conjunction is contingent, it follows from (EP) in its restricted form that $\mathrm{T}$ makes $\langle\mathrm{P} \wedge \mathrm{Q}\rangle$ true. Given that a truthmaker for a conjunction is a truthmaker for each conjunct, T makes $\langle\mathrm{Q}\rangle$ true (Restall 1996, p. 334).
} 
The idea here is that truthmaking is a non-monotonic relation in that if $\langle\mathrm{P}\rangle$ is true in virtue of $\mathrm{T}$, it need not follow that $\langle\mathrm{P}\rangle$ is true also in virtue of $\mathrm{T}$ and $\mathrm{X}$, for some arbitrary $\mathrm{X} .{ }^{8}$ For $\mathrm{X}$ to be a part of something in virtue of which $\langle\mathrm{P}\rangle$ is true, $\mathrm{X}$ must play some role in making $\langle\mathrm{P}\rangle$ true. The reason is that ' $\langle\mathrm{P}\rangle$ is true in virtue of $\mathrm{T}$ ' is thought to express a relation of metaphysical explanation between $\langle\mathrm{P}\rangle$ and $\mathrm{T}$. And since all parts of an explanation must be explanatorily relevant, irrelevant additions defeat the initial explanation (Dasgupta 2014, p. 4).

My response to this objection is two-fold. First of all, what is considered appropriate uses of 'in virtue of' rests on intuitions. It might seem odd to claim that a proposition is true in virtue of a more embracing truthmaker when a more discerning one is available. But intuition regarding language use (whether odd or familiar) is a poor guide in metaphysics and most certainly should never be accepted as the sole reason either to affirm or deny a substantive claim. ${ }^{9}$ Secondly, even if intuitions provide prima facie reasons to reject the monotonicity of truthmaking, they do not pose a threat to the present account. For if, like here, true claims of the form ' $\langle\mathrm{P}\rangle$ is true in virtue of $\mathrm{T}$ ' are not taken to express metaphysical explanations (or any kind of explanation for that matter), but are merely conceived of as being underwritten by underlying grounding relations (see e.g. Rodriguez-Pereyra 2005: p. 28), there is no commitment to non-monotonicity to begin with. For according to the present view, grounding is neither identical to the relation of metaphysical explanation nor is it a kind of explanation. Rather, grounding is what makes it possible to provide certain kinds of metaphysical explanation. We may compare this with causation between events, and one event causally explaining another. Causation, thus understood, is neither identical with causal explanation nor is it a kind of explanation. Rather, the causation involved makes the corresponding causal explanation possible by underwriting it. On this view, there is no reason to think that causation 'inherits' the structural properties of explanation. For example, someone who allows for backward causation may, without inconsistency, claim that explanation is an asymmetric relation (and a fortiori, that causal explanation is asymmetric), and yet deny that causation itself exhibits asymmetry. ${ }^{10}$ Similarly, I argue, it might be that while truthmaker explanations are non-monotonic, they are backed up (or underwritten by) relations that themselves aren't (Trogdon 2013). ${ }^{11}$ The only reasons we have been given for thinking that grounding is non-monotonic

\footnotetext{
${ }^{8}$ It is widely thought that 'in virtue of', 'because' and similar locutions are non-monotonic (see e.g. Fine 2012a, p. 56f; 2012b, p. 2, Correia 2010, p. 11f, Schnieder 2011, p. 450, Dasgupta 2014, p. 4 and Kramer and Roski 2015, p. 65).

${ }^{9}$ By letting intuitions on pertinent language use guide us towards an adequate truthmaker theory, we also run the risk of creating an asymmetry between the locutions 'true in virtue of' and 'makes true'. Thus for example, it seems somewhat odd (or misleading) to claim that 〈something exists $\rangle$ is true in virtue of Socrates (or even worse, that Socrates is that in virtue of which 〈something exists〉 is true). And yet, almost everyone agrees that Socrates makes it true that something exists.

${ }^{10}$ See also Ruben's (1990: pp. 219-220) discussion on the connection between the relation of identity and identity explanation.

11 As a matter of fact, the monotonicity of truthmaking (qua grounding) was thought uncontroversial before the explanatory view became the orthodoxy (see e.g. Mulligan et al. 1984, p. 316; Simon 1992, p. 165 and Armstrong 2004, pp. 17-18).
} 
is that grounding proper and metaphysical explanation are one and the same relation or that grounding is some kind of relation of explanation. ${ }^{12}$ If, as here, both of these claims are denied, the rationale for denying monotonicity is lost and any intuitions we have about pertinent uses of 'in virtue of' can be accounted for by our explanatory interests. ${ }^{13}$

In the ensuing discussion I shall assume that grounding proper is monotonic. Moreover, I will assume that the notion of entailment being employed is classical, but restricted to (purely) contingent truths. It is important to note that nothing essential hinges on these assumptions as the following proposal for how to provide grounds for negative truths should stand whether or not truthmaking is monotonic and whatever version of (EP) we accept.

\section{Causal truthmakers}

With these preparations in place, the time has come to discuss the non-truthfunctional complexes whose bespoke truthmakers are able to ground (purely) contingent negative truths. There are, of course, many such complexes. Due to lack of space, I cannot present them all but will limit my discussion to one particular kind of non-truth-functional complex, namely causal reports. More specifically, I will discuss Mellor's non-relational view of causation and argue that the entailment principle (where the principle is acceptable only when restricted to 'purely' contingent truths) allows us to provide grounds for a large set of truths in the truthmakers for various causal claims. The idea is that the grounds for a (purely) contingent negative truth $\langle\sim \mathrm{P}\rangle$ are the entities that make true the causal reports in which $\langle\sim \mathrm{P}\rangle$ occurs either as the stated cause or as the stated effect. And since causal reports are factive, and truthmaking is closed under entailment in the way suggested above, it follows that whatever makes true the causal report also makes true the stated cause and effect.

In his (1995) Mellor argues, against Davidson (1967) and other event-theorists, that causes and effects are facts, in the minimal non-truthmaking sense of 'fact' given by the principle that $\langle\mathrm{P}\rangle$ is true iff it is a fact that $\mathrm{P}$. Following Mellor, let us take the canonical form of a causal report to be:

(CT) $\langle$ E because $\mathrm{C}\rangle$,

where 'because' is a non-truth-functional connective linking $\langle E\rangle$ and $\langle C\rangle$. To take an example, suppose that $\langle$ Socrates dies because he drinks hemlock $\rangle$ is a true causal instance of (CT). The stated effect $\mathrm{E}$ is then the fact that Socrates dies and the stated cause $\mathrm{C}$, the fact that Socrates drinks hemlock. All that is meant by calling the relata

\footnotetext{
12 It should be noted, however, that some philosophers can be read as holding that grounding is both nonmonotonic and a tracking relation (see e.g. Correia 2010, p. 11f; Fine (2012a, p. 56f and 2012b, p. 2) and Dasgupta 2014, p. 4). Unfortunately, none of these authors provides any external justification for nonmonotonicity other than that grounds should be explanatorily relevant to the facts they ground.

13 Thus, for example, once we distinguish between metaphysical explanation and grounding there is no reason to deny that Socrates and Plato taken together makes it true that Socrates exists in that their joint existence provides sufficient ontological ground to make it the case that Socrates exists.
} 
of causation 'facts' in this case is that true instances of (CT) entail both $\langle E\rangle$ and $\langle C\rangle$ : Socrates cannot die because he drinks hemlock if he does not die or does not drink hemlock. But since (CT) is not a complete truth-function of $\langle\mathrm{E}\rangle$ and $\langle\mathrm{C}\rangle$, the reverse fails to obtain: that Socrates dies and that he drinks hemlock does not entail that he dies because he drinks hemlock. True causal instances of (CT) will therefore require complex truthmakers with at least three constituents: two to make $\langle\mathrm{C}\rangle$ and $\langle\mathrm{E}\rangle$ true and a third to make $\langle\mathrm{E}$ because $\mathrm{C}\rangle$ state a causal truth. The relation holding between the first two propositions and their truthmakers is that of determination, as, for example, when $\langle$ Socrates drinks hemlock $\rangle$ and $\langle$ Socrates dies $\rangle$ are respectively made true by the corresponding events or states of affairs (e.g. Socrates' drinking hemlock and Socrates' death). The problematic constituent is the third, the one which, according to Mellor, "adds causation to a world of otherwise causally unrelated facts" (2000, p. 244).

Whatever makes $\langle\mathrm{E}$ because $\mathrm{C}\rangle$ true must be such that it makes $\mathrm{C}$ raise the chance of E. Mellor writes this as ' $c h(\mathrm{E})$ '. This chance (stating an objective probability) is a property of $C$ in conjunction with the circumstances $S$ in which $\langle E$ because $\mathrm{C}\rangle$ is true. ${ }^{14} \mathrm{By}$ ' $\mathrm{C}$ raising the chance of $\mathrm{E}$ ' is meant that the chance of $\mathrm{E}$ given $\mathrm{C}$ is higher than it would be in $\mathrm{S}$ in the absence of $\mathrm{C}$ : formally, $c h_{\mathrm{C}}(\mathrm{E})>c h_{\sim \mathrm{C}}(\mathrm{E})$. The claim is then that these chances are the $p$ and $p^{\prime}$ such that the following conditionals are true in $\mathrm{S}$ :

$$
\begin{aligned}
& \text { (1) } \mathrm{C} \Longrightarrow \operatorname{ch}(\mathrm{E})=p \text { and } \\
& (\sim 1) \quad \sim \mathrm{C} \Longrightarrow \operatorname{ch}(\mathrm{E})=p^{\prime},
\end{aligned}
$$

where ' $\Longrightarrow$ ' is given the possible world semantics of Lewis (1973) by taking (1) and $(\sim 1)$ to be true if and only if their consequents are true in all the worlds closest to the actual world where their antecedents are true. So to understand what makes causal instances of (CT) true we need to know what makes these conditionals true. Fortunately, many well-known facta (sing. factum: Mellor's term for truthmaking states of affairs) fit the bill here. The example Mellor provides is of a massive object $a$ conforming to Newton's Laws of Motion (1995, pp. 171-74). Let 'F' and 'M' range over net forces and values of inertial mass respectively, and let $\mathrm{A}$ be $a$ 's acceleration. The following deterministic instances of $(1)$ and $(\sim 1)$ :

$$
\begin{gathered}
\mathrm{F} a \Longrightarrow \operatorname{ch}(\mathrm{A}=\mathrm{F} / \mathrm{M})=1 \text { and } \\
\sim \mathrm{F} a \Longrightarrow \operatorname{ch}(\mathrm{A}=\mathrm{F} / \mathrm{M})=0,
\end{gathered}
$$

are then made true in $\mathrm{S}$ by $a$ 's having some determinate value $\mathrm{M}$ of $\mathrm{M}$. M $a$ (together with the laws of motion) makes both $(1)$ and $(\sim 1)$ true by making $a$ accelerate at $\mathrm{F} / \mathrm{M}$ when a net force acts on it and not do so when $a$ is not subject to a net force. Similarly in more complex cases, such as the case where the fact that Socrates drinks hemlock raises the chance of him dying - a truth which we may assume is made true, in the relevant circumstances, by the laws of nature together with a large number of atomic states of affairs involving the physical state of Socrates' digestive,

\footnotetext{
${ }^{14} \operatorname{ch}(\mathrm{E})$ cannot be a property of $\mathrm{E}$, since the effect might not exist for $\operatorname{ch}(\mathrm{E})$ to be a property of. This is hardly surprising since $\mathrm{E}$ is a fact if and only if $\langle\mathrm{E}\rangle$ is true, and there might be a chance that $\langle\mathrm{E}\rangle$ is true (where $\operatorname{ch}(\mathrm{E})=p$, such that $p<1$ ) even though $\langle\mathrm{E}\rangle$ is actually false. See Mellor (1995, pp. 21-24).
} 
circulatory, and central nervous system. As in these cases, so in general: whenever there is a true causal instance of (CT), some atomic factum or plurality of such facta joins with the laws of nature to make $(1)$ and $(\sim 1)$ true for some $p$ and $p^{\prime}$, such that $p>p^{\prime}{ }^{15}$

In addition to $\langle\mathrm{E}$ because $\mathrm{C}\rangle$, there are also true causal instances of $(\mathrm{CT})$ with negative reports substituted for $\langle\mathrm{E}\rangle$ and/or $\langle\mathrm{C}\rangle$ as in $\langle$ Socrates does not die because he does not drink hemlock〉, 〈Kim has no children because she uses contraception〉 or 〈there is a famine because there is no water $\rangle$. Again, the stated cause must raise the chance of the effect. So if the form of the causal report is $\langle\sim \mathrm{E}$ because $\sim \mathrm{C}\rangle$, the chance of $\sim \mathrm{E}$ given $\sim \mathrm{C}$ must be higher than it would be if $\mathrm{C}$ : formally, $c h \sim \mathrm{C}(\sim \mathrm{E})>c h_{\mathrm{C}}(\sim \mathrm{E})$. By analogy with $\langle\mathrm{E}$ because $\mathrm{C}\rangle$, these chances are the $p$ and $p^{\prime}$ such that the following holds in $\mathrm{S}$ :

$$
\begin{aligned}
& \sim \mathrm{C} \Longrightarrow \operatorname{ch}(\sim \mathrm{E})=p \text { and } \\
& \mathrm{C} \Longrightarrow \operatorname{ch}(\sim \mathrm{E})=p^{\prime}
\end{aligned}
$$

where these conditionals are made true by some atomic state of affairs (or plurality thereof) together with the laws of nature, such that $p>p^{\prime}$. The truthmakers for the negative reports differ from the positive ones only in that they do not include constituent facta making the negative causes and/or effects true. All it takes for $\langle\sim \mathrm{P}\rangle$ to be true is that nothing makes $\langle\mathrm{P}\rangle$ true-a fact in the non-substantial sense of 'fact' if $\langle\mathrm{P}\rangle$ is false, but not a factum. This, however, does not prevent negative reports from being causal. For if $\mathrm{P}$ is a fact if and only if $\langle\mathrm{P}\rangle$ is true, both $\langle$ Socrates dies because he drinks hemlock〉 and 〈Socrates does not die because he does not drink hemlock $\rangle$ are capable of reporting causal links between facts. The fact that Socrates does not drink hemlock and the fact that he does not die are still facts (albeit negative ones) if the corresponding propositions are true. So the fact (if it is a fact) that $\mathrm{C}$ causes $\mathrm{E}$ cannot stop $\sim \mathrm{C}$ and $\sim \mathrm{E}$ being causally linked when they are facts, i.e. when $\langle C\rangle$ and $\langle E\rangle$ are false. In other words, it is immaterial to causation whether true instances of (CT) state negative or positive causes and/or effects, since the corresponding reports are equally capable of being causal in each case. ${ }^{16}$

To this one might object that if there are true causal instance of (CT) with negative causes and effects, there must be far more causal reports than we normally care to mention. Thus for example, it is true that my orchid is wilting because Barack Obama does not water it; that my skin is not blue because I do not drink colloidal silver; that my room is tidy because there is no hippo in it, and so on. We would ordinarily refrain from making causal judgments like these, even though the stated cause raises the chance of the effect in each case. However, the mere fact that

\footnotetext{
15 It is possible that the laws of nature are metaphysically necessary, and if they are, the atomic states of affairs would suffice to make $(1)$ and $(\sim 1)$ true on their own. For then, since the laws of nature obtain in every possible world, there would be no need to include them in the truthmaker for the conditionals in question.

16 This is not to say that $\langle\mathrm{E}$ because $\mathrm{C}\rangle$ and $\langle\sim \mathrm{E}$ because $\sim \mathrm{C}\rangle$ can be true together-they cannot. However, although $\langle$ Socrates dies because he drinks hemlock $\rangle$ and $\langle$ Socrates does not die because he does not drink hemlock $\rangle$ cannot both be true, Socrates may still die because he drinks hemlock if he drinks hemlock, and not die because he does not drink hemlock if he does not drink hemlock (Mellor 1995, p. 134).
} 
we do not burden our talk with promiscuously many negative causal judgments does not make them any the less true. As David Lewis points out, "There are ever so many reasons for why it might be inappropriate to say something true. It might be irrelevant to the conversation, it might convey a false hint, it might be known already to all concerned" (Lewis 2000, p. 196). ${ }^{17}$

Now, consider $\langle\sim \mathrm{P}\rangle$ and assume that it states an effect in a causal report of the form $\langle\sim \mathrm{P}$ because $\sim \mathrm{Q}\rangle$. What makes it true (if true) is then some factum or plurality of facta which, together with the laws of nature, makes the cause $\sim \mathrm{Q}$ raise the chance of the effect $\sim \mathrm{P}$. This is all there is to the causal truthmaker in question. To make $\langle\sim \mathrm{P}$ because $\sim \mathrm{Q}\rangle$ true, there is no need to include a 'separate' truthmaker for $\langle\sim \mathrm{P}\rangle$ or $\langle\sim \mathrm{Q}\rangle$. It suffices for the truth of the negative propositions that nothing makes the corresponding positive propositions true. But this is no more evidence for negative truths being ungrounded than conjunctive truths lacking conjunctive truthmakers is evidence for true conjunctions being ungrounded. For just as we took the truth of $\langle\mathrm{P} \wedge \mathrm{Q}\rangle$ to be grounded in the truthmakers for $\langle\mathrm{P}\rangle$ and $\langle\mathrm{Q}\rangle$, we can now take the truth of $\langle\sim \mathrm{P}\rangle$ and $\langle\sim \mathrm{Q}\rangle$ to be grounded in the causal truthmaker for $\langle\sim \mathrm{P}$ because $\sim \mathrm{Q}\rangle \cdot{ }^{18}$ All we need to assume is that truthmaking (qua grounding) transmits across entailment in the present case. ${ }^{19}$ For since a true causal instance of (CT) entails its constituent cause and effect (whether positive or negative), whatever makes the former true also makes the latter true. There is thus no need for negative ${ }^{20}$ or totality states of affairs ${ }^{21}$ in addition to what makes causal truths true. Once the

\footnotetext{
17 Notice that Mellor's non-relational view of causation is revisionary. Intuition usually judges negative causal reports to imply moral responsibility. For example, the fact that my child falls off her bike because I do not pay attention makes me morally responsible for her accident. But of course, few philosophers thinks that the moral status of causal reports is relevant to their metaphysical status as causal reports. To think that it is would spread the notion of responsibility around too much-no one would claim that Napoleon or Socrates is responsible for my child's accident, though they both did fail to pay attention to her. I am grateful to an anonymous referee for raising this point (see also Beebee 2004).

18 The conjunction and negation cases differ with respect to grounding only insofar as, in the former case, the ground is a truthmaker for atomic truths, whereas in the latter it is a truthmaker for a non-truthfunctional complex. However, it is not essential to maximalist versions of logical atomism that all truths be grounded in atomic truthmakers. It suffices that each truth is grounded in the existence of truthmakers for non-recursive truths, i.e. truths that are not recursive functions of more atomic truths.

19 This is not to say that whenever A grounds B, and B entails (or necessitates) C, then A grounds C. Grounding is generally thought to be an irreflexive relation. But if grounding transmits across entailment (or necessitation) in the above sense, then we quickly get violations of irreflexivity. For example, Socrates grounds the singleton \{Socrates\}. But \{Socrates\} also necessitates the existence of Socrates. So, if grounding transmits across necessitation, we get the unfortunate result that Socrates grounds himself.

The Entailment Principle, however, does not violate the irreflexivity of grounding. The antecedent of (EP) states a cross-categorial relation that holds between entities belonging to different kinds: a proposition $\langle\mathrm{P}\rangle$ and a non-propositional entity that grounds $\langle\mathrm{P}\rangle$ 's truth. And since entailment is a relation that holds (or fails to hold) solely between propositions, it follows that $\mathrm{T}$ and the proposition $\langle\mathrm{Q}\rangle$ entailed by $\langle\mathrm{P}\rangle$ do not belong to the same kind. Consequently, (EP) is fully compatible with the claim that grounding exhibits irreflexivity. I owe an anonymous referee for this point of clarification.

20 Russell (1956).

21 Armstrong (2004). A worry here is that we still need totality states of affairs to provide truthmakers for universal quantifications. See Stenwall (2016) for why this worry is unwarranted.
} 
latter are grounded, the negative truths are obtained for free, thus reestablishing symmetry in grounding.

So far so good. Still, I take it that most theorists, including those sympathetic to an entailment principle, will not be convinced that causal truthmakers provide us with a rich enough ontology to ground negative truths. I want now to defend causal truthmaking against this charge, and show it to be unsubstantiated. What I hope will emerge is an elegant solution to the problem of negative truths that is both ontologically economical and illuminating.

\section{Grounding on the cheap?}

Causal truthmakers serve to ground several truths. This is hardly a problem. Most theorists agree that a single entity can make multiple truths true-as, for instance, when Socrates makes true both 〈Socrates exists〉 and 〈something exists〉. Conversely, it is generally agreed that a truth can have several truthmakers (e.g. when 〈something exists is made true by everything that exists), as indeed, we would expect the negative truths to have if they are causally grounded. What might be thought problematic, however, is that, unlike truthmakers for standard existential assertions, causal truthmakers fail to necessitate the truth of any of the propositions they make true. This is partly because the states of affairs that join with the laws of nature to make causes raise their effects' chances will do so only contingently upon circumstances that obtain in this world. To illustrate: suppose I am holding a ball in my hands, and that the claim 'the ball does not fall because I do not let go' is a true causal report of the form $\langle\sim \mathrm{E}$ because $\sim \mathrm{C}\rangle$. Its truthmaker, we may assume, is the ball's having mass $M$, which joins with Newton's Law of Gravity to make the cause raise the chance of the effect. The problem is that these states of affairs will only make the corresponding chance-raising-conditionals $(2)$ and $(\sim 2)$ true in circumstances like S (taken to include facts about how I am holding the ball, its distance from the surface of the earth, and so on). In other possible worlds, nomologically identical to ours, the ball's having mass $M$ will not make the stated cause raise the chance of the stated effect. It might be that in those worlds the ball is not subject to a net gravitational field, or that it is held to the ground. In either case, the chance of the ball not falling $(\sim \mathrm{E})$ given that I do not let go $(\sim \mathrm{C})$ will not be any higher than it would be had I let go $(\mathrm{C})$ : formally, $c h_{\sim \mathrm{C}}(\sim \mathrm{E}) \leq c h_{\mathrm{C}}(\sim \mathrm{E})$.

But this failure of necessitation on behalf of causal truthmakers is only a problem if we accept Truthmaker Necessitarianism, i.e. the principle according to which if $\mathrm{T}$ makes $\langle\mathrm{P}\rangle$ true, then it is impossible for $\mathrm{T}$ to exist and for $\langle\mathrm{P}\rangle$ to be false. So what is the motivation for this requirement? Why is it that whenever T makes $\langle\mathrm{P}\rangle$ true, there cannot be any possible world in which $\mathrm{T}$ exists and $\langle\mathrm{P}\rangle$ is false? The only author who has made an effort to answer this question is Armstrong. He argues that if $\mathrm{T}$ makes $\langle\mathrm{P}\rangle$ true but does not necessitate its truth, then $\mathrm{T}$ is merely a proper part of the complete truthmaker for $\langle\mathrm{P}\rangle$. The reason for this, he says, is that:

There will then be at least the possibility that $\mathrm{T}$ should exist and yet the proposition $\mathrm{p}$ not be true. This strongly suggests that there ought to be some 
further condition that must be satisfied in order for $\mathrm{p}$ to be true. This condition must either be the existence of a further entity $U$, or a further truth, q. In the first of these cases, $\mathrm{T}+\mathrm{U}$ would appear to be the true and necessitating truthmaker for p. [...] In the second case, q either has a truthmaker, V, or it does not. Given that $q$ has a truthmaker, then the $T+U$ case is reproduced. Suppose q lacks a truthmaker, then there are truths without truthmakers. The truth q will 'hang' ontologically in the same sort of way that Ryle left dispositional truths hanging. (2004, pp. 6-7).

If Armstrong is right about this, the complete truthmaker for (2) and $(\sim 2)$ in the above case is not merely the ball's having mass $M+$ Newton's Law of Gravity, but these facta together with whatever makes $\mathrm{S}$ true, where $\mathrm{S}$ is the conjunction of relevant facts about the circumstances in which the stated cause raises the chance of the stated effect.

But this argument begs the question. For notice that Armstrong's argument presupposes both that anything which fails to necessitate the truth of a proposition cannot be a truthmaker for that proposition and that anything which necessitates the truth of a proposition must be a truthmaker for that proposition. This is just another way of saying that necessitation is both a necessary and a sufficient condition for making true, which is exactly what the argument is meant to establish (MacBride 2013). So if Armstrong were to insist that the truthmakers for $S$ must be included to yield the complete truthmaker, he would be begging the question. He has yet to show that this supplement needs to be added to the causal truthmaker in order for 'the ball does not fall because I do not let go' to be true, and until he does so there is no reason to assume that truthmakers must necessitate truth. As a matter of fact, truthmaking is primarily a matter of grounding truth, and as I have argued elsewhere, grounding is a primitive dependency relation that neither reduces to nor implies necessitation (Stenwall 2016). ${ }^{22}$

To this one might object that causal truthmaking is in fact much weaker than what the above argument suggests. For suppose that we add the truthmaker for the circumstances $\mathrm{S}$ to our alleged causal truthmaker. Does it follow that they together necessitate the truth of 'the ball does not fall because I do not let go'? Well, suppose that the causation involved here is an irreducibly probabilistic phenomenon. In that case the alleged truthmaker will only guarantee the chance-raising, not whether the proposition in question is true or not. But if so, causal truthmakers would make the proposed account compatible with truth not being supervenient on being. After all, in indeterministic contexts, the account allows for possible worlds to differ with respect to truth and falsity without thereby differing with respect to existence. Prima facie, this seems highly implausible, as it is generally agreed that the groundedness of truth commits us to the principle that truth supervenes on what exists (see e.g. Bigelow 1988, p. 125).

\footnotetext{
22 To this one might object that if we are left without any positive conception of truthmaking in terms of necessitation, we do not know what is at stake when it is claimed that something suffices to make a certain truth true. Due to lack of space, I cannot address this objection here. For a detailed discussion of why it is mistaken, see Skiles (2015) and Stenwall (2016).
} 
My response to this objection is to deny that there is such a commitment. The reason for this is that the quest for finding grounds for truth is primarily a quest for finding dependency relations between true propositions and that upon which their truth depends. But dependency ought not to yield anything like supervenience (Stenwall 2016). This requires some unpacking. To see what I have in mind, consider John Hawthorne's article on chances and counterfactuals (2005), where he argues that Lewis's framework for providing truth-conditions for counterfactual claims in terms of similarity relations obtaining between possible worlds is mistaken, and that our position in modal space is not determined by what actually exists. In a discussion on the semantics of counterfactual claims in probabilistic contexts, Hawthorne recommends repainting the traditional picture offered by modal realists. His own preference is to opt for a picture similar to that of Stalnaker's (1968) according to which, for any world $w$ and possibility that $\mathrm{P}$, there is a unique closest world to $w$ where it is true that P. But then, consider the case in which it is assumed to be true of our ball that had it been dropped, it would have fallen to the ground. Let us furthermore assume that the counterfactual is made true in the actual circumstances by the ball's having mass $M+$ Newton's Law of Gravity. If we accept interpretations of quantum mechanics according to which the wave function for a system delivers irreducible probabilities of location, there is a small objective chance of some bizarre events unfolding. The ball being dropped may approximate a deterministic system but never fully reach it. Although it is an extremely small chance, there $i s$ the chance that the ball, when dropped, never falls to the ground-it might hover in mid-fall, fly off sideways, turn into dust before reaching the ground, etc. Suppose that the object is not dropped. According to Hawthorne's semantics, if the closest world in which the object is dropped is also a world where the object falls to the ground, the counterfactual is true. Otherwise it is false. There is nothing in the actual world to determine which of these two worlds is the closest. Consequently, on this view, indeterministic contexts allow for pairs of indiscernible worlds that differ with respect to what is true in them. But, of course, this just tells us that in determining what might be the case the actual world does not suffice. If the ball is not dropped and the world is irreducibly indeterministic, there is, under the actual circumstances, a minute chance that it would not be true that were the ball to be dropped, it would have fallen to the ground. This cannot be ruled out. However, it does not follow from this that the counterfactual is true independently of what reality is like. For when it is true, the counterfactual will depend for its truth on the ball having determinate mass $M$ attracting other masses in accordance with Newton's Law of Gravity. This is what grounds its truth and that which underwrites the explanation of why it is true in the actual circumstances that had the ball been dropped it would have fallen to the ground.

One is, of course, perfectly free to deny Hawthorne's non-verificationist analysis of counterfactual discourse (my own preference is for a semantics much closer to Lewis's). My intention is merely to draw attention to the fact that the groundedness of truth is fully compatible with truth failing to supervene on what exists. Expanding on this idea, we get that if some truthmaker $\mathrm{T}$ grounds the truth of $\langle\mathrm{P}\rangle$, it does not follow that if $\langle\mathrm{P}\rangle$ had not been true, $\mathrm{T}$ would not have existed. In indeterministic contexts it suffices that $T$ raises the chance of $\langle P\rangle$ being true. In other words, the 
chance of $\langle\mathrm{P}\rangle$ being true must be higher than it would be had T not existed. But this lack of determination on behalf of the truthmakers does not pose a problem for truthmaker theory; for truth will still depend on existence. If indeterminism in physics has a bearing on grounding, this merely goes to show that some truths are not supervenient on being in that their truth-value is not held fixed by what there is. Each truth, whether it is about (or underwritten by) the outcome of unactualized deterministic or indeterministic phenomena, will still depend for its truth upon that which grounds its truth. And the relevant notion of entailment that is in play here is that of a dependency relation. It is as Rodriguez-Pereyra puts it, the notion that "truth depends on being, in that it is grounded on being-being is the ground of truth" (2002: p. 33).

Another worry I want to address briefly is that there might not be enough causal truthmakers out there to ground every (purely) contingent negative truth. Are there causal grounds for the truth of the propositions that there is not a flying spaghetti monster or that Barack Obama does not water my plants? The first thing to notice is that if truthmaking distributes across entailment with respect to negative truths, then providing truthmakers for such truths is far less of an ontological burden than it otherwise would be. For, assuming some plausible version of (EP), the grounds for negative truths would also serve to ground the truth of the proposition(s) it entails. Thus, for example, since $\langle$ no one waters my plants $\rangle$ entails $\langle$ Barack Obama does not water my plants $\rangle$, there is no need for a separate truthmaker for the latter proposition if the former is already grounded. The second thing to notice is that if there are (purely) contingent negative truths which fail to be causally grounded, there will have to be some non-reified way the world is that does not occur in any pattern of causal dependence. But such facts (in the non-reified sense of 'fact') would be naturalistically queer. They would be causally disconnected from every other fact, so we would have to accept that there are contingent propositions which state facts with no causal bearing on any other fact. Thus, unless we allow for 'causal danglers' into our ontology, we would expect causal truthmaking to be general enough to cover all (purely) contingent negative truths. ${ }^{23}$ Of course, it might be that I am wrong about this. For all we know, it might be that there is nothing causal to account for the truth of the proposition that space-time is not Euclidean (assuming that it is a contingent truth) or for negative truths about epiphenomena. However, nothing of what I have said requires all negative truths to have causal grounds. For theoretic purposes, it suffices that all negative truths are grounded in the truthmakers for some non-truth-functional complex or other, which seems undeniable. ${ }^{24}$

\footnotetext{
${ }^{23}$ Identifying grounds for negative truths is an empirical matter that sometimes requires extensive research. Thus for example, it has been shown that what sets a limit to observed biodiversity is a highly complex interplay between evolutionary mechanisms that set a boundary to the routes that evolution might take within a defined space of possible forms (Prusinkiewicz et al. 2007). It seems reasonable to assume that mechanisms like these provide causal grounds for truths denying the existence of, say, unicorns, centaurs, mermaids etc.

${ }^{24}$ Due to lack of space I cannot argue this point in further detail. Suffice it for present purposes to stress the fact that in order for there to be ungrounded negative truths some such truths would have to be such that they are not entailed by any non-truth-functional complex. This seems highly unlikely. Just think of all the true non-causal explanations involving the locution 'because', the fact that true instances of
} 


\section{Summary}

Causal truthmaking has a number of virtuous consequences. Molnar (2000, pp. 84-85) famously argued that at least one of the following claims must be rejected if we are to have truthmakers for negative truths: (i) the world is everything that exists; (ii) everything that exists is positive; (iii) some negative claims about the world are true; and (iv) every true claim about the world is made true by something that exists. I think that this is false. Having already accepted (iii) and (iv), we are left to account for (i) and (ii). Consider (i). The acceptance of a reading of ' $\Longrightarrow$ ' that pertains to Lewis's possible world semantics does not commit one to the existence of possible worlds between which primitive relations of closeness obtains (Mellor 2000 , pp. 244-45). The truthmakers for true causal instances of $(1),(\sim 1),(2)$ and $(\sim 2)$ are all inhabitants of the actual world. In accounting for the truth of negative propositions we can, therefore, remain actualists; we are not forced to give up (i).

Now take (ii), the claim that everything that exists is positive. This is undoubtedly the most dubious of Molnar's claims. What does it mean? I take it that there is no way to extrapolate the sense in which existents are positive from positive propositions. Any such attempt would raise, needlessly, difficult questions concerning general principles of demarcation: does not 〈Socrates is dead $\rangle$ negatively represent it not being the case that Socrates is alive and /Socrates is not dead > positively represent it being the case that Socrates is alive? What is it then for some existent entity to be positive? The only sense I can think of is that existent entities are positive in that they satisfy the Eleatic Principle that causal powers are the mark of being (or rather of positive being). Anything that can properly be said to have 'negative existence', such as lacks, absences and negative states of affairs, is negative in virtue of not having causal powers. This interpretation seems to accord well with Molnar's discussion of the acausality of the negative (Molnar 2000, pp. 77-80). If this is along the right lines, the causal facta making negative propositions true are undoubtedly positive. I conclude, therefore, that causal truthmakers enable us to retain all four of Molnar's claims without inconsistency. All we need are the positive first-order states of affairs that contribute to the causal order of the world, and such causal facts are needed anyway to provide grounds for a large set of truths. They are useful, for example, when we are seeking to identify grounds for truths about rainbows and mirror images (see Mellor 2002b). The rainbow that is not at any specific distance from the observer does not exist; nor does the object behind the mirror appearing to be reversed. Truths about rainbows are grounded in various causal facta involving water-drops refracting and reflecting light. Similarly, truths about mirror images are grounded in causal truthmakers involving objects reflecting light in front of the mirror (Persson 2006, p. 546).

Open Access This article is distributed under the terms of the Creative Commons Attribution 4.0 International License (http://creativecommons.org/licenses/by/4.0/), which permits unrestricted use,

Footnote 24 continued

$\langle c h(\sim \mathrm{P})=1\rangle$ entails $\sim \mathrm{P}$ (Mellor 1995, p. 31) and the fact that there are more (factive) non-truthfunctional complexes than can be dreamt of by language users. 
distribution, and reproduction in any medium, provided you give appropriate credit to the original author(s) and the source, provide a link to the Creative Commons license, and indicate if changes were made.

\section{References}

Armstrong, D. M. (2004). Truth and truthmakers. Cambridge: Cambridge University Press.

Beebee, H. (2004). Causing and nothingness. In J. Collins, N. Hall, \& L. A. Paul (Eds.), Causation and Counterfactuals (pp. 291-308). Cambridge: MIT Press.

Bigelow, J. (1988). The reality of numbers: A physicalist's philosophy of mathematics. Oxford: Oxford University Press.

Cameron, R. (2008). How to be a truthmaker maximalist. Noûs, 42(3), 410-421.

Correia, F. (2010). Grounding and truth-functions. Logique et Analyse, 53, 251-279.

Dasgupta, S. (2014). On the plurality of grounds. Philosopher's Imprint, 14(20), 1-28.

Davidson, D. (1967). Causal relations. Journal of Philosophy, 64, 691-703.

Fine, K. (2012a). Guide to ground. In F. Correia, \& B. Schnieder (Eds.), Metaphysical grounding: Understanding the structure of reality (pp. 37-80). Cambridge: Cambridge University Press.

Fine, K. (2012b). The pure logic of ground. The Review of Symbolic Logic, 5(1), 1-25.

Hawthorne, J. (2005). Chance and counterfactuals. Philosophy and Phenomenological Research, 70, 396-405.

Kramer, S., \& Roski, R. (2014). A note on the logic of worldly ground. Thought, 4, 59-68.

Lewis, D. (1973). Counterfactuals. Oxford: Blackwell.

Lewis, D. (2000). Causation as influence. Journal of Philosophy, 97, 182-197.

MacBride, F. (2013). Truthmakers. Stanford Encyclopedia of Philosophy. http://plato.stanford.edu/ entries/truthmakers/.

Mellor, D. H. (1995). The facts of causation. London: Routledge.

Mellor, D. H. (2000). The point of refinement. Analysis, 60(3), 243-246.

Mellor, D. H. (2002a). Real metaphysics: Replies. In H. Lillehammer, \& G. Rodriguez-Pereyra (Eds.), Real metaphysics (pp. 212-238). London: Routledge.

Mellor, D. H. (2002b). Truth-makers. Unpublished manuscript.

Molnar, G. (2000). Truthmakers for negative truths. Australasian Journal of Philosophy, 78, 72-86.

Mulligan, K., Simons, P., \& Smith, B. (1984). Truth-makers. Philosophy and Phenomenological Research, 44(3), 287-321.

Persson, J. (2006). Compartment causation. Synthese, 149, 535-550.

Prusinkiewicz, P., Erasmus, Y., Lane, B., Harder, L. D., \& Coen, E. (2007). Evolution and development of inflorescence architectures. Science, 316, 1452-1456.

Read, S. (2000). Truth-makers and the disjunction thesis. Mind, 109, 67-79.

Restall, G. (1996). Truth-makers, entailment and necessity. Australasian Journal of Philosophy, 74, 331-340.

Rodriguez-Pereyra, G. (2002). Resemblance nominalism: A solution to the problem of universals. Oxford: Oxford University Press.

Rodriguez-Pereyra, G. (2005). Why truthmakers? In H. Beebee, \& J. Dodd (Eds.), Truthmakers (pp. 17-31). Oxford: Oxford University Press.

Rodriguez-Pereyra, G. (2006). Truthmaking, entailment, and the conjunction thesis. Mind, 115(460), 957-982.

Rodriguez-Pereyra, G. (2015). Grounding is not a strict order. Journal of the American Philosophical Association, 1(3), 517-534.

Ruben, D.-H. (1990). Explaining explanation. London: Routledge.

Russell, B. (1956). Logic and knowledge. London: Allen and Unwin.

Schaffer, J. (2009). On What Grounds What. In D. Chalmers, D. Manely, \& R. Wesserman (Eds.), Metaphysical grounding: Understanding the structure of reality (pp. 122-138). Cambridge: Cambridge University Press.

Schnieder, B. (2011). A logic for 'because'. The Review of Symbolic Logic, 4(3), 445-465.

Simon, P. (1992). Logical atomism and its ontological refinement. Language, Truth and Ontology, 51, $157-179$.

Skiles, A. (2015). Against grounding necessitarianism. Erkenntnis, 80, 717-751. 
Stalnaker, R. (1968). A theory of conditionals. Oxford: Blackwell.

Stenwall, R. (2016). Against truthmaker necessitarianism. Logique et Analyse, 59(233), 37-54.

Trogdon, K. (2013). An introduction to grounding. In M. Hoeltje, B. Schnieder, \& A. Steinberg (Eds.), Varieties of dependence: Ontological dependence, grounding, supervenience, response dependence (Basic Philosophical Concepts) (pp. 97-122). Philosophia Verlag. 